\title{
Analisis Struktur dan Nilai Teks Mitos Sang Naga Rarik di Pura Luhur Mekori
}

\author{
Ni Luh Putu Dewi Kartika Sari*, Ida Bagus Rai Putra, T. I. A. Mulyawati R. \\ Program Studi Sastra Bali, Fakultas Ilmu Budaya, Universitas Udayana \\ [dewikartika2402@gmail.com],[rai_putra@unud.ac.id], \\ [tiamulya59@gmail.com] \\ Denpasar, Bali, Indonesia \\ *Corresponding Author
}

\begin{abstract}
This study aims to examine the Mythical Texts of the Dragons Rarik in Luhur Mekori Temple, Belimbing Village, Pupuan District, Tabanan Regency Structure and Value Analysis. The purpose of this study is to describe the narrative structure that builds this mythical text and find out what values are contained in it. This study using two theories namely, structural theory and value theory. The methods and techniques used in this study consist of three stages, namely Methods and Techniques of providing data using observation and interview methods that assisted by recording techniques and translation techniques. Methods and data analysis techniques using qualitative methods with descriptive analytic techniques. Methods and Techniques of presenting the results of data analysis using informal methods supported by inductive and deductive techniques. The results that can be obtained in this study are the narrative structure that builds the mythical texts of the Naga Rarik in Pura Luhur Mekori, specifically incidents, plots, character and characterization, setting themes, and mandates. Besides, this study also knows the values contained in this mythical text, namely religious values (magical values and belief values), and ethical values.
\end{abstract}

Keywords: myth, narrative structure, and value

\begin{abstract}
Abstrak
Penelitian ini bertujuan untuk mengkaji mengenai Teks Mitos Sang Naga Rarik di Pura Luhur Mekori Desa Belimbing, Kecamatan Pupuan, Kabupaten Tabanan Analisis Struktur, dan Nilai. Tujuan penelitian ini adalah untuk mendeskripsikan struktur naratif yang membangun teks mitos ini dan mengetahui nilai-nilai apa saja yang terkandung didalamnya. Dalam penelitian ini menggunakan dua teori yaitu, teori struktural dan teori nilai. Metode dan teknik yang digunakan dalam penelitian ini terdiri dari tiga tahapan, yaitu Metode dan Teknik penyediaan data menggunakan metode observasi dan metode wawancara, yang dibantu dengan teknik pencatatan, teknik perekaman, dan teknik terjemahan. Metode dan Teknik analisis data menggunakan metode kualitatif dengan teknik deskriptif analitik. Metode dan Teknik penyajian hasil analisis data menggunakan metode informal yang didukung dengan teknik induktif dan teknik deduktif. Adapun hasil yang dapat diperoleh dalam penelitian ini adalah struktur naratif yang membangun teks mitos Sang Naga Rarik di Pura Luhur Mekori yaitu insiden, alur/plot, tokoh dan penokohan, latar, tema, dan amanat. Selain itu dalam
\end{abstract}

\begin{tabular}{lll}
\hline Info Article & & \\
\hline Received & $:$ & $19^{\text {th }}$ December 2019 \\
Accepted & $:$ & $6^{\text {th }}$ November 2020 \\
Published & $:$ & $30^{\text {th }}$ November 2020
\end{tabular}


penelitian ini juga mengetahui nilai yang terkandung dalam teks mitos ini, yaitu nilai agama (nilai magis, dan nilai kepercayaan), dan nilai etika.

Kata kunci: mitos, struktur naratif, dan nilai.

\section{PENDAHULUAN}

Mitos yang dikaji dalam penelitian ini adalah teks mitos Sang Naga Rarik di Pura Luhur Mekori. Keberadaan Pura Luhur Mekori ini terletak di pinggir jalan raya utama Tabanan-Pupuan, tepatnya di Desa Belimbing, Kecamatan Pupuan, Kabupaten Tabanan. Pura Luhur Mekori memiliki latar belakang dan kisah yang unik, dan berada di kawasan hutan tropis.

Keunikan dan keistimewaan yang terdapat dalam teks mitos Sang Naga Rarik di Pura Luhur Mekori ini dimana pura tersebut diyakini sebagai tempat bekas lubang yang dilalui oleh Naga Rarik untuk memasuki Sapta Patala menyatu dengan Ibu Pertiwi (Moksa), bekas lubang tersebut tumbuh pohon Bunga Soka Bang yang berwarna merah. Keunikan dan keistimewaan lainnya, setiap dilakukan piodalan yang jatuh pada Rahina Buda Kliwon Gumbreg ada tarian khusus yaitu tari Rejang Lilit atau Renteng yang merupakan rangkaian dari upacara piodalan di Pura Luhur Mekori. Tari wali Rejang Lilit atau Renteng ini merupakan tarian yang wajib di Pura Luhur Mekori yang selalu dipentaskan pada akhir rangkaian upacara piodalan. Tari Rejang Lilit atau Renteng ini ditarikan oleh penari laki atau perempuan baik anak kecil maupun orang dewasa dalam jumlah puluhan orang menari. Tarian ini berfungsi sebagai pemuput karya yang diawali dengan adanya Sesuunan yang turun (tedun) sebagai penuntun dilaksanakan tarian tersebut, tarian itu mengelilingi areal pura sebanyak tiga kali dengan diiringi oleh kidung warga sari (lagu-lagu suci) dengan membawa lelontek, tombak, pengawin, dan tedung. Tidak hanya itu, Pura Luhur Mekori ini dipercaya oleh umatnya setiap melewati pura, baik yang ke utara maupun ke selatan selalu melakukan persembahyangan karena dipercaya untuk memohon perlindungan dan kesejahteraan agar selalu di lindungan oleh Ida Betara yang berstana di pura tersebut.

Salah satu bagian dari folklore adalah cerita prosa rakyat, dapat dibagi menjadi tiga golongan, yaitu : (1) mite (myth), (2) legenda (legend), (3) dongeng (folktale). Mite yaitu cerita prosa rakyat yang benarbenar terjadi serta dianggap suci, dan ditokohi oleh para dewa atau makhluk setengah dewa William R. Bascom (dalam Danandjaja, 1984:50). Mitos ialah lambang yang tidak disadari oleh masyarakat (Johari, 2016:33) Mitos ialah suatu cerita tentang dewa serta pahlawan-pahlawan zaman dahulu (Pratiwi, 2017:2). Cerita rakyat merupakan suatu kekayaan yang dimiliki oleh masyarakat atas dasar keinginan sosial masyarakat (Maziyah, 2019:13). Pemahaman mitos dengan mitologi sangat berbeda karena memiliki pembeda yang mendasar (Roibin, 2010:87). Mitos merupakan aktifitas dewa, oleh karena itu mitos disakralkan dan menyikapi kesakralan (Ekowati, 2019:8).

Penelitian ini akan menonjolkan warisan budaya Bali yang ada sejak nenek moyang, yaitu teks mitos Sang Naga Rarik di Pura Luhur Mekori Desa Belimbing, sampai saat ini dipercaya oleh masyarakat di sana sebagai tempat Puser Jagat dari Sang Naga Rarik, dengan tumbuhnya bunga Soka Bang yang selalu disucikan dan disakralkan, yang dipercayai oleh 
pemujanya untuk memohon kesejahteraan dan perlindungan. Penelitian Pura Luhur Mekori sudah pernah dilakukan sebelumnya dalam analisis Hutan Pura Mekori di Desa Belimbing Kecamatan Pupuan Tabanan dalam kajian Etnoekologi Hindu. Penelitian tersebut dilakukan oleh I Wayan Sutadana yang mengkaji mengenai bentuk pelestarian hutan dan fungsi hutan yang ada di Desa Belimbing. Sedangkan penelitian terhadap teks mitos Sang Naga Rarik di Pura Luhur Mekori ini belum pernah ada yang menggarap atau mengkaji sebelumnya sebagai objek penelitian. Adapun permasalahan yang diperoleh dalam penelitian ini yaitu berupa kajian struktur pembangun teks ialah insiden, alur, tokoh dan penokohan, latar, tema dan amanat, dan nilai-nilai yang terkandung didalamnya berupa nilai agama (magis dan kepercayaan), dan nilai etika, penelitian ini juga bertujuan untuk mempublikasikan teks mitos sang naga rarik kepada masyarakat agar potensi yang terdapat di dalamnya diketahui dan dimanfaatkan oleh masyarakat luas.

\section{METODE}

Metode dan teknik yang digunakan dalam penelitian ini ialah Metode dan Teknik Penyediaan Data menggunakan metode observasi dan menggunakan metode wawancara yang mewawancarai narasumber untuk mengetahui cerita mitos. Teknik yang digunakan dalam penyediaan data yaitu menggunakan teknik rekam, teknik catat, serta teknik terjemahan.

Metode dan Teknik Analisis Data yang digunakan ialah metode kualitatif, metode ini memanfaatkan cara tafsiran yang disajikan berbentuk deskripsi. Metode kualitatif merupakan cara-cara perhatian pada data ilmiah dengan konteks keadannya (Dendriani, 2016:99). Sedangkan teknik yang digunakan yaitu teknik deskriptif analitik. Teknik deskriptif analitik dilakukan dengan cara mendeskripsikan terlebih dahulu kemudian dianalisis

Metode dan Teknik Penyajian Hasil Analisis Data yang digunakan metode informal, menurut Sudaryanto (dalam Ratna, 2004:50) mengatakan, metode informal ialah dengan cara penyajian yang melalui kata-kata biasa. Sedangkan teknik dalam penyajian hasil analisis data digunakan teknik deduktif yaitu teknik yang penyajiannya bersifat dari umum ke khusus sebagai penjelas dan teknik induktif yaitu teknik yang penyajiaannya dari khusus ke umum.

\section{KERANGKA TEORI}

Penelitian mengenai Teks Mitos Sang Naga Rarik di Pura Luhur Mekori ini akan menggunakan teori struktural dan teori nilai. Struktural karya sastra dapat dilakukan dengan identifikasi, mengkaji dan deskripsi fungsi serta hubungan antar unsur intrinsik yang bersangkutan. Pertama-tama diidentifikasi dan dideskripsikan, semisal bagaimana kejadian, plot, tokoh dan penokohan, sudut pandang, dan lain sebagainya. Setelah dijelaskan bagaimana peran masing-masing unsur itu ketika menunjang makna keseluruhannya, dan betapa hubungan antar unsur itu sehingga secara bersamasama mewujudkan seluruh totalitas kemaknaan yang padu. jika bagaimana hubungan antara peristiwa yang satu dengan yang lainnya kaitan dengan pemplotan yang tidak selalu berurutan, kaitannya dengan tokoh dan penokohan, dengan latar dan sebagainya (Nurgiyantoro, 1995:37). Struktur merupakan sesuatu cara dapat dibangun pada pola-pola tertentu (Malawat, 2017:2)

Karya sastra dibangun oleh unsurunsur yang menjadi satu kesatuan yang 
utuh. Uraian aspek intrinsik karya sastra adalah uraian yang mengenai karya-karya sastra itu sendiri, tanpa melihat kaitannya dengan data di luar cipta karya-karya itu. Mengenai sistematika aspek intrinsik yang dipaparkan yakni (1) unit-unit cipta sastra seperti insiden, plot, karakterisasi, (2) cerita teknik, (3) komposisi cerita, serta (4) gaya bahasa, (Sukada, 1987:29). Teori Struktural ialah penunjang utama suatu alat (Lado, 2016:6)

Menurut Atmaja (1988:14), mengatakan bahwa nilai tidak lain dari persepsi dan pengertian yang diperoleh penyimak melalui suatu karya sastra yang disimaknya, karena itu suatu karya sastra mungkin dapat menawarkan nilai kesenangan, informative cultural, dan keseimbangan wawasan, yang terakhir ini digunakan seorang penyimak untuk menilai kehidupan, dapat memilih responrespon emosionalitas, rangsangan aksi yang mungkin berbeda dengan yang dialaminya. Pengertian suatu nilai pada karya sastra lama, lisan atau tulis ialah elemen esensi membentuk secara keseluruhan (Rosmana, 2010:194)

Nilai ialah tingkat kebijaksanaan, kebaikan, serta kegunaan yang dimiliki. Satu nilai bisa diturunkan pada konsep seorang akan objek yang adiluhung, kemanusiaan, berkualitas, dan mulia. Nilai ini dapat digolongkan menjadi empat : (a) nilai agama meliputi nilai religius, magis, kepercayaan, dan spiritual; (b) nilai logika meliputi nilai intertual, ilmiah (pengetahuan), dan empiris; (c) nilai etika meliputi nilai moral, sopan santun, manusiawi, etis, dan lain-lain; (d) nilai estetika meliputi nilai keindahan, keseimbangan, keanggunan, keasrian, dan lain-lain (Yudibrata, dalam Atmaja, 1988:21).

\section{HASIL DAN PEMBAHASAN}

\section{Struktur Naratif Teks Mitos Sang Naga Rarik}

Struktur naratif yang membangun teks mitos Sang Naga Rarik pembahasan pertama tentunya akan diawali pada analisis insiden kemudian dilanjutkan dengan alur/plot, tokoh dan penokohan, latar, tema dan amanat. Struktural Levi Strauus merupakan analisis berupa transformasi, relasi, serta oposisi yang terdapat pada sikap perilaku antartokoh (Putro dkk, 2014:79). Karya sastra merupakan bagian dari cerita rakyat yang bermanfaat bagi pembaca karena memiliki stuktur yang jelas (Isnanda, dkk, 2015:187).

\section{Menurut Sukada}

$(1982: 22)$

mengatakan insiden ialah masalah-masalah atau kejadian yang terjadi ketika suatu cerita tak bergantung pada panjang dan pendek, yang secara utuh membangun kerangka struktur cerita menyeluruh. Dalam teks mitos Sang Naga Rarik di Pura Luhur Mekori terdapat delapan insiden yang membangun. Insiden yang pertama ialah suatu ketika ibunya yang sedang pergi ke hutan untuk mecari kayu bakar ketika ingin pulang pengrupak miliknya hilang yang entah tertinggal di mana, lalu ia mengucapkan janji. Insiden kedua ialah kejadian yang dimana I Meme melihat sekor ular yang besar di dalam gua yang sedang melilit pengrupaknya sesuai dengan janjinya ia langsung melakukan hubungan layaknya suami istri. Insiden ketiga ialah anaknya selalu bingung melihat ibunya yang setiap bangun pagi selalu pergi ke lumbung padi. Insiden keempat ialah ketika kedua anaknya yang menggoreng telur akibat perselingkuhan ibuknya dengan ular itu, suatu keajaiban datang ketika telur itu matang di taruh di atas piring menjadi satu piring penuh, hanya 
kakaknya yang laki memakan telur itu, seketika seluruh tubuhnya bersisik seperti ular. Insiden kelima adalah atas petuah tetua di desanya, disuruh untuk memohon maaf dan memohon ampun dengan melaksanakan semadi kehadapan Tuhan Yang Maha Esa, pada saat melakukan semadi mereka diberikan petunjuk bahwa kedua anaknya ditakdirkan sebagai junjungan untuk menjaga dan memberikan kesejahteraan bagi umat yang memujanya disyaratkan untuk mencari tempat puser jagat. Insiden keenam adalah terjadinya permusuhan antara Sang Naga Rarik dengan Sang Naga Gombang yang tidak bisa diakhiri karena setiap bertemu selalu berkelahi, sehingga Sang Naga Rarik ingin membalas dendam untuk menentukan kalah atau menang sampai ada yang meninggal. Insiden Ketujuh adalah sudah berhari-hari Sang Naga Rarik berkelahi dengan Sang Naga Gombang tidak menghitung terang ataupun gelap, alhasil pertarungan tersebut dimenagkan oleh Sang Naga Rarik. Insiden kedelapan adalah Sang Naga Rarik sudah menemukan tempat yang akan dijadikan Puser Jagat yang dekat dengan pasar, ketika adiknya yang datang dari membeli jajan tape adiknya tidak menemukan kakaknya lagi hanya dilihat bekas bolongan yang dilalui oleh Sang Naga Rarik menuju Sapta Patala, kemudian Ayu Mas Sari diminta melaksanakan Semadi di hulu bolongan tersebut kemudian Ayu Mas Sari sampai meninggal di areal yang persis, akan kehendak Tuhan Yang Maha Esa areal tersebut ditumbuhi Pohon Bunga Soka Bang yang bunganya berwarna Merah.

Menurut Nurgiyantoro (1995:110), alur (plot) ialah bagian fiksi yang terpenting, tidak sedikitpun orang-orang yang menganggapnya sebagai sesuatu yang terpenting antara berbagai bagian fiksi yang lainnya. Alur (plot) yang terdapat pada teks mitos Sang Naga Rarik dimulai dari tahap awal, yaitu tahap situasion (penyituasian), di sebuah desa ada keluarga yang melakoni hidup sederhana yang bekerja sebagai petani. Pada tahap generating circumstances (pemunculan konflik) ketika kedua anaknya yang menggoreng telur akibat perselingkuhan ibuknya dengan ular itu, suatu keajaiban datang ketika telur itu matang di taruh di atas piring menjadi satu piring penuh, hanya kakaknya yang laki memakan telur itu, seketika seluruh tubuhnya bersisik seperti ular. Pada tahap racing action (peningkatan konflik) pada saat ibunya mengakui atas perbuatannya yang memadu kasih dengan I Lelipi tempo hari, lalu bapaknya mengusir ibunya, dan bapaknya langsung meminta nasehat dari tetua desa. Pada tahap climax (klimaks) saat Sang Naga Rarik berubah wujud pada saat itu ia dendam dan benci dengan Sang Naga Gombang, akibat perbuatan Sang Naga Gombang mereka mesti ditinggalkan ibunya, saat kejadian tersebut timbul perseteruan Sang Naga Rarik dan Sang Naga Gombang tidak dapat diselesaikan dikarenakan setiap berjumpa kerap bertarung. Pada tahap denouement (penyelesaian) Sang Naga Rarik sudah menemukan tempat yang akan dijadikan Puser Jagat yang dekat dengan pasar.

\section{Menurut Sukada}

$(1987: 135)$

menyebutkan, perwatakan mempunyai tiga sudut pandang seperti struktur utama saat membangun suatu karya sastra, ialah: 1) Fisikologis, yakni cacat tubuh, tampang, jenis kelamin, dan lain-lain, 2) Psikologi, yakni ambisi, kekecewaan, cita-cita, dan lain sebagainya, 3) Sosiologis, meliputi kebangsaan, agama, pangkat, lingkungan, dan lainnya. Tokoh merupakan rekaan individu dalam mengalami suatu kejadian yang terjadi dalam suatu peristiwa (Sari, 2018:530) Teks mitos Sang Naga Rarik di 
Pura Luhur Mekori Desa Belimbing di dalamnya terdapat tokoh-tokoh yang terdiri atas tokoh utama yaitu Sang Naga Rarik dan Ayu Mas Sari dilihat dari dimensi Psikologis dan dimensi Sosiologis, tokoh sekunder yaitu I Meme dilihat dari dimensi Psikologis dan dimensi Sosiologis dan I Lelipi (Sang Naga Gombang) dilihat dari dimensi Sosiologis, dan tokoh pelengkap yaitu Bapane dilihat dari dimensi Psikologis dan panglingsir desa dilihat dari dimensi Sosiologis.

Menurut Nurgiyantoro (1995:227) menyatakan, elemen latar atau setting terdiri dari tiga unsur pokok yakni tempat, waktu, dan sosial. . Latar dalam teks mitos Sang Naga Rarik di Pura Luhur Mekori Desa Belimbing menggunakan tiga latar yaitu latar tempat, terdapat dua belas latar tempat yaitu Ring Desa Kentel Gumi, Ka Alase, Di Tengah Goane, Ka Gelebeg, di Tuban, di Enjung Kuta, Di Bongkol Gunung Batukaru, Pura Batur Pemandekan, Pura Bedugul, Ring Pasar, Puser Jagat, dan Ring Pura Luhur Mekori, kemudian terdapat empat latar waktu yaitu Duk Ipidan, Sedek Dina Anu, Kala, dan Lemah lan Peteng, dan latar sosial terdapat sistem kepercayaan masyarakat.

Menurut Nurgiyantoro

(1995:71) menyatakan, tema ialah hal-hal yang paling terpenting dalam suatu cerita, dapat dikatakan bahwa tema merupakan rangkuman pada keseluruhan isi dari cerita. Tema suatu karya-karya sastra sering berhubungan pada pengalaman kehidupan. Tema yang terkandung dalam teks mitos Sang Naga Rarik di Pura Luhur Mekori Desa Belimbing adalah karmaphala, yang dimana karmaphala yang digambarkan dari Prarabda Karma Phala perbuatan buruk dari ibunya yang diterima oleh Sang Naga Rarik hasilnya juga di terima sekarang akibat dari perbuatan ibuknya Sang Naga Rarik berubah menjadi seekor naga yang harus mencari tempat Puser Jagat.

Nurgiyantoro (1995:320) amanat disebut dengan moral. Moral ialah suatu yang akan diungkapkan oleh pengarang untuk pembaca, ialah makna dapat terkandung pada suatu karya-karya sastra, makna dapat disarankan melalui cinta. Amanat dalam teks mitos Sang Naga Rarik di Pura Luhur Mekori Desa Belimbing disampaikan secara implisit dan eksplisit. Implisit atau tersembunyi yaitu pada pengarajan moral dapat tersirat pada perilaku tokoh, pada rangkaian dialog ataupun percakapan tokoh. Amanat yang terkandung secara eksplisit yaitu disampaikan secara larangan, seruan, anjuran, nasehat, saran peringatan, serta berkenaan pada gagasan yang mendasari sebuah cerita.

\section{Nilai Teks Mitos Sang Naga Rarik}

Menurut Atmaja, 1988:21), menyatakan bahwa nilai ialah tingkat kebijaksanaan, kebaikan, serta kegunaan yang dimiliki. Satu nilai bisa diturunkan pada konsep seorang akan objek yang adiluhung, kemanusiaan, berkualitas, dan mulia. Merumuskan nilai pokok dalam suatu karya sastra yakni: nilai logika, nilai agama, nilai estetika, serta nilai etika. Dari keempat nilai itu dijabarkan kembali menjadi: 1) nilai agama: a) magis, b) religius, c) spiritual, dan d) kepercayaan. 2) nilai logika: a) intelektual, b) ilmiah, c) empiris. 3) nilai etika: a) moral, b) sopan santun, c) manusiawi, d) etis. 4) nilai estetika: a) keindahan, b) keseimbangan, c) kesegaran, d) hiburan, e) keasrian, f) keanggunan, g) keagungan. Nilai merupakan aspek-aspek kehidupan yang dibutuhkan (Cahyanti, 2017:14).

Nilai-nilai yang terkandung dalam teks mitos Sang Naga Rarik di Pura Luhur Mekori Desa Belimbing meliputi nilai 
agama: nilai magis adanya kekuatan gaib yang tidak masuk akal apabila sebutir telur dimasak ditaruh di piring dan pane/jamban hasilnya berbeda, dan kehendak dari Ida Sang Hyang Widhi Wasa bekas lubang yang dilalui oleh Naga Rarik dan adiknya ditumbuhi pohon bunga Soka Bang yang buganya berwarna merah, konon sekarang bunga tersebut tumbuh berwarna kuning emas. Jika magis bertemu dengan yang nyata serta hadir menjadi sesuatu yang tak bisa dihindari (Widijanto, 2018:106). Dan nilai kepercayaan yakni percaya dengan Sang Hyang Widhi Wasa warga Desa Belimbing pengempon Pura Luhur Mekori percaya bahwa yang dipuja di sana ialah Ratu Bagus Made Mentang Yuda wujud dari Naga Rarik dan adiknya Ayu Mas Sari, yang sampai saat ini warga Desa Belimbing maupun masyaraka luar selalu memohon perlindungan dan kesejahteraan kepada Beliau agar selalu dijaga dalam melakukan suatu kegiatan. Dan percaya dengan adanya karma phala yaitu setiap hasil perilaku yang kita perbuat baik ataupun buruk, termasuk ke dalam Prarabda Karma Phala, yang digambarkan pada pada buah dari perbuatan ibunya yang telah menyebabkan anak laki-lakinya berubah menjadi seekor naga, yang menyebabkan anaknya ditakdirkan sebagai junjungan untuk menjaga dan memberikan kesejahteraan bagi umat yang memujanya disyaratkan untuk mencari tempat puser jagat dan menyatu pada Ibu Pertiwi atau Moksah. Kepercayaan masyarakat merupakan seseorang yang mempunyai sifat leluhur pada hidupnya yang masih mempercayai dengan adanya suatu upacara ritual (Amaliyah, 2018:403)

Nilai etika terdapat ajaran moral tentang perbuatan yang baik digambarkan pada saat mereka menggoreng telur itu banyak keanehan yang terjadi, sehingga kakaknya melarang adiknya untuk ikut memakan telur itu, perbuatan yang kurang baik (buruk) digambarkan Sang Naga Rarik sangat benci dan dendam dengan Sang Naga Gombang karena telah meyebabkan mereka kehilagan ibunya, sehingga Sang Naga Rarik ingin membalas dendam untuk menentukan kalah atau menang sampai ada yang meninggal, serta kesetiaan dalam teks mitos Sang Naga Rarik di Pura Luhur Mekori Desa Belimbing terdapat Satya Semaya (setia terhadap janji) yang digambarkan pada saat ibunya yang setia terhadap janjinya, yang mengambil perumpaknya itu adalah seekor ular lalu ia sanggup berhubungan layaknya sebagai suami istri. Dan Satya Mitra (setia terhadap teman) digambarkan kakaknya yang menjadi Naga sangat setia kawan mengikuti adiknya, walaupun mereka berubah wujud adiknya selalu menyayangi dan menghormati kakaknya.

\section{SIMPULAN}

Berdasarkan uraian yang sudah dipaparkan di atas, kesimpulan dapat ditarik berdasarkan atas masalah-masalah pada penelitian adalah sebagai berikut.

Analisis struktur teks mitos Sang Naga Rarik di Pura Luhur Mekori Desa Belimbing memiliki struktur lengkap yang terdiri dari delapan insiden, alur yang digunakan ialah alur maju, tokoh serta penokohan terdapat tokoh serta penokohan tokoh utama, tokoh serta penokohan tokoh sekunder, dan tokoh serta penokohan tokoh pelengkap, latar dalam teks mitos Sang Naga Rarik di Pura Luhur Mekori Desa Belimbing yang menggunakan tiga latar yakni latar tempat, latar waktu, dan latar sosial, tema yang terkandung dalam teks mitos Sang Naga Rarik di Pura Luhur Mekori Desa Belimbing adalah karmaphala, serta amanat yang terkandung dalam teks mitos Sang Naga Rarik di Pura 
Luhur Mekori Desa Belimbing disampaikan secara implisit dan eksplisit.

Nilai-nilai yang terkadung dalam teks mitos Sang Naga Rarik di Pura Luhur Mekori Desa Belimbing ini memakai teori nilai menurut Yudibrata, yaitu nilai agama yang meliputi (nilai kepercayaan dan nilai magis), dan nilai etika, yang dimana kedua nilai tersebut yang membangun struktur dalam teks mitos Sang Naga Rarik di Pura Luhur Mekori Desa Belimbing.

\section{REFERENSI}

Amaliyah, Efa Ida. 2018. Nilai-Nilai Kearifan Lokal dalam Tradisi Perang Obor di Tegalsambi-Jepara sebagai Karakteristik Islam Nusantara. Lektur Keagamaan Vol 16.2. Kudus: Dosen IAIN Kudus, Jawa Tengah.

Atmaja, Jiwa. 1988. Masyarakat Sastra Indonesia. Denpasar: Himsa.

Cahyanti, Ika. 2017. Mitos dalam Ritual Ruwatan Masyarakat Madura di Kecamatan Gending Kabupaten Probolinggo. Edukasi Vol IV.1. Jember: Jurusan Pendidikan Bahasa dan Seni, FKIP UNEJ.

Danandjaja, James. 1984. Folklor Indonesia (Ilmu Gosip, Dongeng, dan lain-lain). Jakarta : PT. Grafis Pers.

Dendriani, I Gusti Ayu. 2016. Teks Bulan Mekalangan Karya I Nyoman Manda; Analisis Struktur dan Nilai. Humanis Vol 17.1. Denpasar: Sastra Bali Fakultas Ilmu Budaya Universitas Udayana.

Ekowati, Yunik. 2019. Mitos dalam Pertunjukan Tari Wanara Parisuka dalam Ritual Sesaji Rewanda di Goa Kreo Semarang. Imaji Vol 17.1. Semarang: Universitas Negeri Semarang.
Isnanda, Romi, dkk. 2015. Struktur dan Nilainilai Pendidikan dalam Cerita Rakyat Kabupaten Tanah Datar Provinsi Sumatera Barat. Gramatika Vol 1.2. Padang: Program Studi Pendidikan Bahasa dan Sastra Indonesia Fakultas Keguruan dan Ilmu Pendidikan Universitas Bung Hatta.

Johari, Arief. 2016. Representasi Mitos dan Makna pada Visual Lambang Daerah. Ritme Vol 2.1. Bandung: Fakultas Seni dan Desain Universitas Pendidikan Indonesia.

Lado, Susana Fitriani. 2016. Analisis Struktur dan Nilai-nilai Moral yang terkandung dalam Cerpen Ten Made Todoke Karya Yoshida Genjiro. Japanese Literature Vol 2.2. Semarang: Jurusan S1 Sastra Jepang FIB Universitas Diponegoro.

Malawat, Insum. 2017. Struktur dan Fungsi Mitos Kerjaan Raja Ampat. Melanesia Vol 1.2. Malang: Program Karya Siswa S3 PPS Universitas Negeri Malang.

Maziyah, Naelil. 2019. Analisis Nilai Spiritual dalam Pembentukan Karakter pada Buku Cerita Rakyatn Karya Wirodarsono. IVCEJ Vol 2.1. Semarang: Jurusan Pendidikan Guru Sekolah Dasar, Universitas PGRI.

Nurgiyantoro, Burhan. 1995. Teori Pengkajian Fiksi. Yogyakarta: Gadjah Mada University Press.

Pratiwi, Mirza Krisna Gita. 2017. Mitos-Mitos di Gunung Lawu: Analisis Struktur, Nilai Budaya, dan Kepercayaan. Bapala Vol 1.1. Surabaya: Pendidikan Bahasa dan Sastra Indonesia, Fakultas Bahasa dan Seni UNS.

Putro, Die Bhakti Wardoyo, dkk. 2014. Pelestarian Warisan Budaya Masyarakat Tionghoa-Jambi dan konfliknya dalam Novel Mempelai Naga 
Karya Meiliana K.Tansri: Pendekatan Struktural Levis Strauus. Caraka Vol 1.1. Yogyakarta: FKIP Universitas Sarjanawijata Tamansiswa.

Ratna, Nyoman Kutha. 2004. Teori, Metode, dan Teknik Penelitian Sastra dari Strukturalisme hingga Perspektif Wacana Naratif. Yogyakarta: Pustaka Pelajar.

Roibin. 2010. Agama dan Mitos: dari Imajinasi Kreatif Menuju Realitas yang Dinamis. el-Harakah Vol 12.2. Malang: Fakultas Syari'ah, Universitas Islam Negeri Malang.

Rosmana, Tjetjep. 2010. Mitos dan Nilai dalam Cerita Rakyat Masyarakat Lampung. Patanjala Vol 2.2. Bandung: Balai Pelestarian Sejarah dan Nilai Tradisional.

Sari, Ni Kadek Surya Dewi Indah. 2018. Teks Mitos Tirta Selaka di Pura Kereban Langit Desa Sading Kecamatan Mengwi: Analisis Struktur dan Fungsi. Humanis Vol 22.2. Denpasar: Sastra Bali Fakultas Ilmu Budaya Universitas Udayana.

Sukada, I Made. 1982. Unsur Insiden dan Perwatakan dalam Fiksi. Denpasar: Majalah Widya Pustaka Fakultas Sastra Universitas Udayana.

Sukada, I Made. 1987. Pembinaan Kritik Sastra Indonesia Masalah Sistematika Analisis Struktur Fiksi. Badung: Angkasa.

Widijanto, Tjahjono. 2018. Dunia Halus Mistis Jawa dan Fantasi Magis Ternate dalam Godlob dan Cala Ibi. Jentera Vol 7.1. Surakarta: Universitas Negeri Sebelas Maret. 